\title{
The Benefit of Integrated Dual Disorders Service Utilization in the Survival of Patients in the Early Stages of Schizophrenia and Co-Occurring Substance use Disorders: a Long-Term Follow-Up Study
}

\author{
Yuri Gimelfarb ${ }^{1 *}$, Alexander Ligay ${ }^{2}$, Julia Jerusalemsky ${ }^{3}$ and Mashit Ben Tzarfati ${ }^{1}$ \\ ${ }^{1}$ AMHC, Bat Yam, affiliated to the Sackler Faculty of Medicine, Tel Aviv University, Israel \\ ${ }^{2}$ KIOR, Almaty, affiliated to the National Medical University, RK \\ ${ }^{3}$ WMC, Holon, affiliated to the Sackler Faculty of Medicine, Tel Aviv University, Israel \\ Submission: July 30, 2017; Published: August 08, 2017 \\ *Corresponding author: Gimelfarb Yuri, AMHC, affiliated to Sackler Faculty of Medicine, Tel Aviv University, Bat Yam 5943602, Israel, Tel: \\ +972 35552749; Email: Ystatist@gmail.com
}

Abstract

Background: Little is known about the impact of integrated dual disorders service (based on social health insurance) utilization by population of dual diagnosis (severe mental illness and co-occurring substance use disorders), in the early stages of illness, on long-term survival.

Objective: To determine the benefit of integrated dual disorders services utilization on long-term survival of these patients in the early stages of schizophrenia and co-occurring substance use disorders.

Methods: The medical records of patients admitted to the Integrated Dual Disorders Treatment Ward (IDDTW) from January 1, 2002 to December 31, 2006 were assessed. Psychiatric diagnoses had been established according to the International Classification of Diseases and Health related Problems $-10^{\text {th }}$ edition. The Kaplan-Meier Survival Analysis was used to estimate the cumulartive survival rates in all the subpopulations, and the risk of all-cause mortality was as $\urcorner$ sessed by Cox proportional-hazards regression models, with and without time-dependent covariates.

Results: During the 10.8-year median follow-up of 275 patients (of them 239 (86.9\%) males), 63 (22.9\%) patients died. In a timedependent adjusted regression models, more than one year of cumulative length of stay (HR=2.48; $95 \%$ CI 1.42 to $4.34 ; p<.0001)$ and more than 2 admissions(HR=1.90; 95\% CI 1.02 to 3.54; $\mathrm{p}<.001$ ) in standard psychiatric inpatient services before the $1^{\text {st }}$ admission in integrated dual disorders treatment ward were significant predictors of higher all-cause mortality.

Conclusion: In order to facilitate accessible and available care, and to increase the long-term survival rates for these patients, the development and expansion of licensed integrated dual disorders inpatient services is recommended.

Keywords: Service utilization; Integrated dual disorders services; Benefit; all-cause mortality; Long-term follow-up; Kaplan-Meier survival analysis; Cox proportional-hazard regression model

Abbreviations: IDDTW: Integrated Dual Disorders Treatment Ward; ICD-10: International Classification of Diseases and Health Related Problems-10 Edition; DSM-IV-TR: Diagnostic and Statistical Manual of Mental Disorders, $4^{\text {th }}$ Edition, Text Revised; ATD: Admission, Discharge and Transfer Program; IQR: Inter-Quartile Range; HR: Hazard Risk; 95\% CI: 95\% Confidence Interval; HBV: Hepatitis B Virus Monoinfection; HCV: Hepatitis C Virus Monoinfection; HBV/HCV: HBV/HCV Co-Infection; LOS: Length of Stay

\section{Introduction}

\section{First-episode schizophrenia-related psychosis and co- occurring substance use disorders}

The research on first-episode psychosis emphasizes the importance of early and appropriate interventions to initiate remissions and to prevent relapses [1-3]. The literature on first-episode psychosis highlights the high prevalence and adverse consequences of substance use, misuse, or disorder $[4,5]$. Significant proportions of patients have use disorders related to alcohol [4,6], cannabis [4-7],cocaine, amphetamines, barbiturates, and other drugs [2,4,5,7]. Overall, approximately half of all clients with first episodes of psychosis present for treatment with a current substance use disorder. 
Schizophrenia with co-occurring substance use disorders is associated with multiple adverse outcomes, including treatment non adherence [2], recurrent admissions[4,6], violence [8], relapse [6] and suicide attempts [9], as well as medical problems such as HIV and viral hepatitis [10,11], and increased all-cause mortality $[12,13]$. The course of substance use disorders in this population tends to be chronic and relapsing $[14,15]$. Traditional parallel treatment approaches (in separate settings) have been established as beingineffective and fragmented, and result in treatment non adherence and dropout $[16,17]$.

\section{Integrated dual disorders services}

The negative outcomes associated with traditional approaches in the treatment of dual disorders led in the 1980s to integrated treatments designed to target co-occurring mental and substance use disorders concurrently in the same setting $[18,19]$. Several reviews of experimental and quasi-experimental studies support different types of integrated treatment, including group counseling, contingency management, residential treatment, and motivational interventions combined with cognitive-behavioral treatment $[17,20]$.

The 1994 National Health Insurance Law stated that healthcare in Israel would be "based on the principle of justice, equality and mutual assistance".

Unfortunately, in the area of mental health care, the treatment of substance use disorders has been characterized by neglect; the budget is minimal and treatment has been focused primarily on drug detoxification programs [21]. This can be seen clearly in the area of integrated treatment of comorbid mental and substance use disorders where the number of offered treatments has been very restricted; only 2 open wards for inpatient treatment in government mental health centers and 20 community care beds. As a result, patients with dual diagnoses have been forced to be hospitalized in standard psychiatric inpatient services; in mental health centers or general hospitals [22,23].

Integrated inpatient care has not been found to be better than mixed care (life-time integrated dual disorders inpatient services and standard psychiatric wards) in the prevention of long-term all-cause mortality [13]. Nevertheless, little is known about the long term survival rates in patients with schizophrenia and co-occurring substance use disorders in the early stages: with and without admissions in integrated dual disorders services. The objective of this study was to determine the benefit of integrated dual disorders services utilization in the early stages of schizophrenia and co-occurring substance use disorders on these patients' long-term survival.

\section{Materials and Methods}

\section{Study design}

This was a retrospective analysis of prospectively collected data. This study was approved by the Institutional Review Board and conducted according to the World Medical Association
Declaration of Helsinki -ethical principles for medical research involving human subjects.

\section{Study participants}

To participate in the study patients had to meet the followed inclusion criteria:

a) Age: 18-65 years old;

b) Both genders;

c) be members of any one of the health funds in Israel: Clalit, Maccabi, Leumit and Meuchedet;

d) Admitted at least once to the Integrated Dual Disorders Treatment Ward (IDDTW) in our center between January 1, 2002 (opening of the IDDTW) and December 31, 2006;

e) With or without lifetime admissions to the other inpatient services within our center or other facilities;

f) Schizophrenia spectrum disorders (F20-F25) according to the International Classification of Diseases and Health related problems- $10^{\text {th }}$ edition (ICD-10);

g) Substance dependence/addiction according to the Diagnostic and Statistical Manual of Mental Disorders, $4^{\text {th }}$ edition, text revised (DSM-IV-TR);

h) All types of admissions (voluntary, forced, mixed);

i) With or without Methadone or Buprenorphine or Buprenorphine/Naloxone (detoxification or maintenance) treatment;

j) With or without any type of psychopharmacological treatment.

Exclusion criteria were:

a) The absence of Israeli citizenship during the admission (tourists, refugees, work seekers);

b) Patients admitted during the study period only for general psychiatric examination requested by authority (with or without lifetime admissions to the other psychiatric facilities).

Details of the study design have been described elsewhere $[12,13]$. All the subsequent patients meeting the study criteria were assessed.

\section{Assessments}

The clinical data, including the date of the first admission to the IDDTW, was obtained from "Prometheus - clinical charts", 14.3thversion". All the patients were clinically monitored as part of the clinical process during the admission. The data on death dates were obtained from the information data base of the admission, discharge and transfer (ATD) program. The date of the first admission at the IDDTW was the date of the beginning of the follow-up in this study. Census date of survival was on July 


\section{Global Journal of Addiction \& Rehabilitation Medicine}

$1^{\text {st }}, 2015$ or the date of the end of the follow-up, whichever came first. Urine was assessed using immune chromatographic analysis for psychoactive substances (Tetrahydrocannabinol-50, heroin, cocaine, amphethamine, methamphethamine, methadone and benzodiazepines).

\section{Outcome measure}

All-cause mortality [11-13,24-28] since January 1, 2002.

\section{Statistical analysis}

Data were analyzed using the Statistical Package for Social Sciences version 20.0 for Windows (SPSS, An IBM Company, version 20). Categorical variables have been presented by frequency tables (numbers with percentages). Continuous variables have been presented by median with range and interquartile range (IQR).The survival analysis was performed by the Kaplan-Meier method (using Log Rank test). The Cox proportional-hazard models with Hazard Risk (HR) and 95\% Confidence Interval ( $95 \% \mathrm{CI}$ ) were used to assess the risk of allcause mortality, with and without time-dependent covariates. P-values less than 0.05 were considered to be statistically significant.

\section{Results}

\section{Study population}

The study population consisted of 275 patients who met the inclusion / exclusion criteria (Table 1). The median age of patients was 33.2 years (range 18.7 - 64.6 years) at the beginning of the follow-up, of them 239 (86.9\%) were males. The majority of patients (54.9\%) were insured by the Clalit health fund. Median observation time was 10.8 years (range .06 - 13.5 years; IQR 8.9 - 12.4 years). Out of patient population 63 (22.9\%) patients died. The median length of stay in standard psychiatric inpatient services before the first admission in IDDTW was 0.4 years (range 0.0 - 30.7 years). The median number of admissions in standard psychiatric inpatient services before the first admission in IDDTW was 4.0 admissions (range 0.0 - 95.0).

Table 1: Demographics and clinical characteristics of patient population $(\mathrm{N}=275)$.

\begin{tabular}{|c|c|}
\hline Variables & Value \\
\hline Gender, males - n (\%) & $239(86.9)$ \\
\hline Age at entry, median years (IQR) & $33.2(26.0-40.9)$ \\
\hline Sickness fund, n (\%) & $151(54.9)$ \\
\hline Clalit & $75(27.5)$ \\
\hline Maccabi & $28(10.2)$ \\
\hline Leumit & $21(7.6)$ \\
\hline Meuchedet & $0.4(0.04-1.6)$ \\
\hline $\begin{array}{c}\text { Length of stay (LOS) before IDDTW, median years } \\
\text { (IQR) }\end{array}$ & $4.0(1.0-8.0)$ \\
\hline $\begin{array}{c}\text { Number of previous admissions in standard } \\
\text { psychiatric wards before IDDTW, median number } \\
\text { (IQR) }\end{array}$ & \\
\hline
\end{tabular}

\begin{tabular}{|c|c|}
\hline $\begin{array}{c}\text { Lifetime mixed care in integrated dual disorders } \\
\text { services and standard psychiatric wards, } \mathrm{n}(\%)\end{array}$ & $230(83.6)$ \\
\hline $\begin{array}{c}\text { Admissions in children/adolescent psychiatric } \\
\text { wards }\end{array}$ & $25(9.1)$ \\
\hline Main psychiatric diagnosis & $220(80.0)$ \\
\hline Schizophrenia & $42(15.3)$ \\
\hline Schizoaffective disorders & $11.0(4.0)$ \\
\hline Acute and transient psychotic disorders & $2(0.7)$ \\
\hline Persistent delusional disorders & $74(26.9)$ \\
\hline Dissocial personality disorder & $218(79.3)$ \\
\hline Viral hepatitis infection & $7(2.5)$ \\
\hline No & $35(12.7)$ \\
\hline HBV monoinfection & $15(5.5)$ \\
\hline HCV monoinfection & $4(1.5)$ \\
\hline HBV/HCV co-infection & \\
\hline Human immunodeficiency virus / acquired & \\
\hline immunodeficiency syndrome & \\
\hline
\end{tabular}

Forty five patients (16.4\%) had lifetime admissions in integrated dual disorders services only. The discharge of the last of them was at May1, 2008. The most frequent main psychiatric diagnosis was schizophrenia $(n=220 ; 80.0 \%)$. Seventy four patients $(26.9 \%)$ had Dissocial personality disorder of all the patients, 15 (5.5\%) presented with hepatitis B virus and hepatitis $\mathrm{C}$ virus (HBV/HCV) co-infection. Four patients $(1.5 \%)$ had human immunodeficiency virus / acquired immunodeficiency syndrome. One hundred and forty seven patients (53.5\%) had lifetime positive results for psychoactive substances in urine analysis. Out of them, 87 patients (59.1\%) had positive results for more than one substance.

\section{Admissions in standard psychiatric inpatient services before the $1^{\text {st }}$ admission in IDDTW and long-term survival}

The number of previous admissions (as continuous variable) in standard psychiatric inpatient services before the $1^{\text {st }}$ admission in IDDTW has not been found to be predictive of longterm survival, neither in time-independent (NS) nor in timedependent unadjusted models (NS). The variable admissions in standard psychiatric inpatient services before the 1st admission in IDDTW was redefined into dichotomy variables: yes vs. no, more than 1 admission vs. others, more than 2 admissions vs. others, more than 3 admissions vs.. others, more than 4 admissions vs. others (Table 2).

From the data presented in Table 2, it can be seen that the strongest prediction of long-term survival has been detected by the dichotomy variable "more than 2 admissions vs.. others": in time-independent (HR=1.98; 95\% CI 1.14 to 3.46; $\mathrm{p}<.001$ ), time-dependent unadjusted (HR=1.98; $95 \%$ CI 1.14 to 3.46 ; $\mathrm{p}<.001)$ and time-dependent adjusted models (HR=1.90; $95 \%$ CI 1.02 to $3.54 ; \mathrm{p}<.001$ ). It was the only variable that 
significantly associated with all-cause mortality in all of the models, mentioned above. For patients, that had more than 2 admissions in standard psychiatric inpatient services before the $1^{\text {st }}$ admission in IDDTW the hazard ratio was 1.90 times higher (95\% CI 1.02 to 3.54; $\mathrm{p}<.001$ ) than for patients with 2 and fewer admissions in standard psychiatric inpatient services before the 1st admission in IDDTW, in the time-dependent adjusted model.

Table 2: Relative risk, by admissions before the 1st admission in IDDTW $(\mathrm{N}=275)$, HR $(95 \% \mathrm{Cl})$.

\begin{tabular}{|c|c|c|c|}
\hline $\begin{array}{c}\text { Admissions } \\
\text { before IDDTW }\end{array}$ & $\begin{array}{c}\text { Time- } \\
\text { independent } \\
\text { (unadjusted) }\end{array}$ & $\begin{array}{c}\text { Time- } \\
\text { dependent } \\
\text { (unadjusted) }\end{array}$ & $\begin{array}{c}\text { Time- } \\
\text { dependent } \\
\text { (adjusted) }\end{array}$ \\
\hline $\begin{array}{c}\text { Yes (n=216) vs } \\
\text { no (n=59) }\end{array}$ & $\begin{array}{c}1.10(.59- \\
2.07)\end{array}$ & $\begin{array}{c}1.10(.59- \\
2.07)\end{array}$ & $.94(.45-1.94)$ \\
\hline $\begin{array}{c}\text { 1 admission } \\
(\mathrm{n}=180) \text { vs } \\
\text { others (n=95) }\end{array}$ & $\begin{array}{c}1.55(.88- \\
2.74)\end{array}$ & $\begin{array}{c}1.55(.88- \\
2.74)\end{array}$ & $\begin{array}{c}1.46(.78- \\
2.74)\end{array}$ \\
\hline $\begin{array}{c}>2 \text { admissions } \\
(\mathrm{n}=161) \text { vs } \\
\text { others (n=114) }\end{array}$ & $* * 1.98(1.14-$ & $* * 1.98(1.14-$ & $* 1.90(1.02-$ \\
$3.46)$ & $3.46)$ & $3.54)$ \\
\hline $\begin{array}{c}>3 \text { admissions } \\
(\mathrm{n}=142) \text { vs } \\
\text { others (n=133) }\end{array}$ & $* 1.66(.99-$ & $* 1.66(.99-$ & $1.48(.84-$ \\
$2.77)$ & $2.77)$ & $2.61)$ \\
\hline $\begin{array}{c}>4 \text { admissions } \\
(\mathrm{n}=121) \text { vs } \\
\text { others (n=154) }\end{array}$ & $\begin{array}{c}1.42(.87- \\
2.34)\end{array}$ & $\begin{array}{c}1.42(.87- \\
2.34)\end{array}$ & $\begin{array}{c}1.22(.72- \\
2.08)\end{array}$ \\
\hline
\end{tabular}

${ }^{*} p<.05$

** $p<.01$

$* * * p<.001$

Adjusted for gender, age at entry, sickness fund, type of life-time care, Dissocial personality disorder, viral hepatitis and HIV.

\section{Length of stay (LOS) before the $1^{\text {st }}$ admission in IDDTW and long-term survival}

LOS (as continuous variable) before the $1^{\text {st }}$ admission in IDDTW has not been found to be predictive of the longterm survival, neither in time-independent (NS) nor in timedependent unadjusted models (NS). The variable LOS before admission in IDDTW was redefined into dichotomy variables: yes vs. no, LOS more than 0.5 year vs. others, LOS more than 1 year vs. others, LOS more than 2 years vs. others, LOS more than 3 years vs. others (Table 3 ).

From the data presented in Table 3, it can be seen that the strongest prediction of long-term survival has been detected by the dichotomy variable "LOS more than 1 year vs. others": in time-independent (HR=2.46; 95\% CI 1.50 to $4.04 ; \mathrm{p}<.0001)$, time-dependent unadjusted ( $\mathrm{HR}=2.48 ; 95 \% \mathrm{CI} 1.51$ to 4.06 ; $\mathrm{p}<.0001$ ) and time-dependent adjusted models (HR=2.48; 95\% CI 1.42 to $4.34 ; \mathrm{p}<.0001)$. It was the only variable which has statistically significant association with all-cause mortality in all of the models, mentioned above. For patients, that have LOS more than one year before admissions in IDDTW the hazard ratio was 2.48 times higher ( $95 \%$ CI 1.42 to 4.34 ; $<<.0001)$ than for patients with LOS of one year or less before admissions in IDDTW, in time-dependent adjusted model.

Table 3: Relative risk, by LOS before the 1st admission in IDDTW $(\mathrm{N}=275), \mathrm{HR}(95 \% \mathrm{Cl})$.

\begin{tabular}{|c|c|c|c|}
\hline LOS & $\begin{array}{c}\text { Time- } \\
\text { independent } \\
\text { (unadjusted) }\end{array}$ & $\begin{array}{c}\text { Time- } \\
\text { dependent } \\
\text { (unadjusted) }\end{array}$ & $\begin{array}{c}\text { Time- } \\
\text { dependent } \\
\text { (adjusted) }\end{array}$ \\
\hline $\begin{array}{c}\text { Yes (n=229) vs } \\
\text { no (n=46) }\end{array}$ & $.88(.46-1.68)$ & $.88(.46-1.69)$ & $.75(.34-1.64)$ \\
\hline $\begin{array}{c}>0.5 \text { year } \\
(n=130) \text { vs } \\
\text { others (n=145) }\end{array}$ & $\begin{array}{c}1.62(.98- \\
2.67)\end{array}$ & $\begin{array}{c}1.62(.98- \\
2.67)\end{array}$ & $\begin{array}{c}* 1.76(1.003- \\
3.09)\end{array}$ \\
\hline $\begin{array}{c}>1 \text { year (n=82) } \\
\text { vs others } \\
(\mathrm{n}=193)\end{array}$ & $* * * 2.46(1.50-$ & $* * * 2.48(1.51-$ & $* * 2.48(1.42-$ \\
$4.04)$ & $4.06)$ & $4.34)$ \\
\hline $\begin{array}{c}>2 \text { years } \\
(\mathrm{n}=52) \text { vs } \\
\text { others (n=223) }\end{array}$ & $* 1.85(1.08-$ & $* 1.86(1.08-$ & $* 1.92(1.02-$ \\
$3.17)$ & $3.18)$ & $3.60)$ \\
\hline $\begin{array}{c}>3 \text { years } \\
(\mathrm{n}=36) \text { vs } \\
\text { others (n=239) }\end{array}$ & $\begin{array}{c}1.71(.93- \\
3.14)\end{array}$ & $\begin{array}{c}1.71(.93- \\
3.15)\end{array}$ & $\begin{array}{c}1.58(.77- \\
3.23)\end{array}$ \\
\hline
\end{tabular}

${ }^{*} p<.05$

${ }^{* *} p<.01$

*** $p<.001$

$\wedge p<.06$

Adjusted for gender, age at entry, sickness fund, type of life-time care, Dissocial personality disorder, viral hepatitis and HIV.

Survival rates of subjects who were hospitalized for up to, or more than, one year, in standard psychiatric inpatient services, at various follow-ups, can be seen in Table 4. From this table, it can be seen that survival rates at 5, 10 and 12 years in population with more than one year of hospitalization was $85.4 \%, 67 \%$ and $54 \%$ respectively. The survival rate of those subjects who had been hospitalized for up to one year, at 5, 10 and 12 year follow-up, was $90.2 \%, 83.7 \%$ and $82.8 \%$ respectively. There was a statistically significant difference in the survival rates between the two sub populations ( $\mathrm{X} 2$ of Log Rank = 13.7; df=1, p<.0001) see Figure 1.

Table 4: Survival time, according to LOS before admission in IDDTW $(\mathrm{N}=275)$.

\begin{tabular}{|c|c|c|c|c|c|}
\hline \multirow{2}{*}{ L0S } & \multicolumn{5}{|c|}{ Survival rates, \% } \\
\cline { 2 - 6 } & 1-year & 5-year & 10-year & 11-year & 12-year \\
\hline $\begin{array}{c}\text { < 1 year } \\
\text { (n=193) }\end{array}$ & 97.4 & 90.2 & 83.7 & 82.8 & 82.8 \\
\hline $\begin{array}{c}>1 \text { year } \\
\text { (n=82) }\end{array}$ & 95.2 & 85.4 & 67.0 & 64.9 & 54.0 \\
\hline
\end{tabular}

Survival rates computed using the Kaplan-Meier method

X2 of Log Rank = 13.7; df = 1; $p<.0001$. 


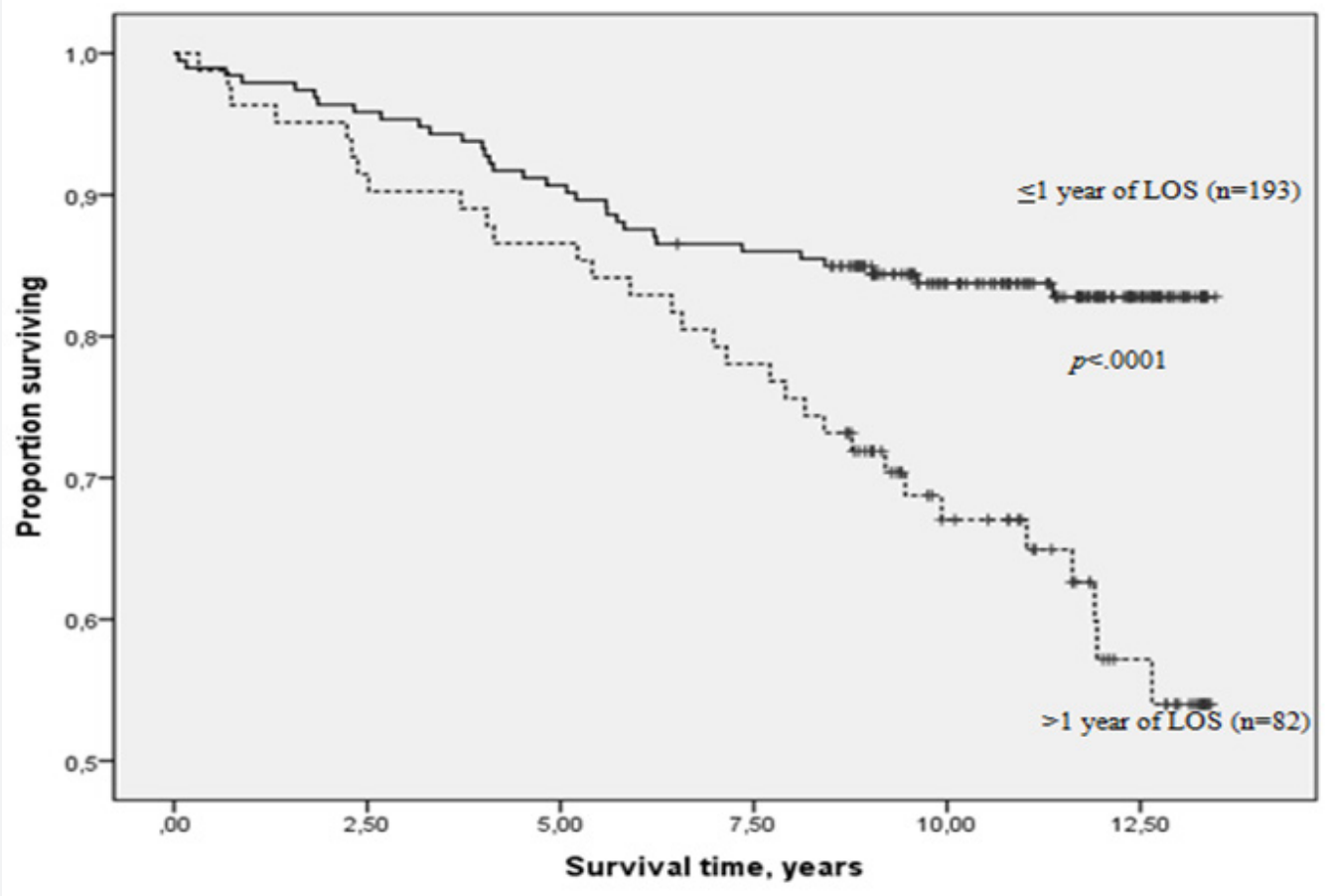

Figure 1: The probability of survival according to LOS before admission in IDDTW (N=275).

\section{Discussion}

The current study focused on the benefit of integrated dual disorders service utilization in the prevention of all-cause mortality among schizophrenic patients who also suffered from comorbid substance use early in their illness. This was assessed by means of follow up for more than 10 years, before the initiation of the largest reform in mental health services ever in Israel [29]. One of the main findings in this study was that those schizophrenic patients who had NOT used the integrated dual disorders inpatient services for their comorbid disorders during the first two hospitalizations for their illness had a 90\% higher risk of mortality than those patients who DID use them. Another central finding from our study was that schizophrenic comorbid patients who did NOT use the integrated dual disorders inpatient services during the first cumulative year of hospitalizations had a $148 \%$ higher risk of mortality than those DID use them.

To the best of our knowledge, there is no other scientific evidence of the benefit of early integrated treatment of comorbid schizophrenia and substance use disorders in the prevention of all-cause mortality in this population of patients with unique treatment requirements. Among the reasons for the association of this kind of treatment with lower mortality at follow up, one may be able to discern the following factors. First, during integrated treatment the patient is exposed early in their illness to a variety of treatments that, together, can prevent all-cause mortality at follow-up: 12-step program, motivational interviewing, the adoption of healthy behavior patterns, the elimination of harmful health habits, appropriate pharmacological treatments (both for the mental illness and the substance use disorders), e.g. drug rehabilitation and drug toxicity treatment $[17,18,29-31]$.

Second, transfer to a personally tailored treatment facility for continued treatment after hospitalization, and NOT to a standard psychiatric treatment framework, e.g. a therapeutic community facility; maintenance outpatient treatment for drug substitute treatment (e.g. Methadone or Buprenorphine or Buprenorphine/Naloxone); a residence hostel for those suffering from dual diagnosis; a community clinic for dual diagnosis patients; day treatment for dual diagnosis [29] third a longer period of hospitalization in a dual diagnosis inpatient unit than in a general psychiatric unit. This can lead to increased compliance, longer exposure to a variety of treatments than is available in a standard psychiatric service [18,30,31].

It should be noted that the sub-population that was studied in the present research was hospitalized in standard psychiatric departments not only before special dual diagnosis services began to open, but also after they were opened, and for a number of years after that. It cannot be excluded that this happened because of a lack of awareness among the treatment staff in the standard psychiatric departments that there was a dual diagnosis diagnostic entity. That said, the main reason for this phenomenon lies in the acute shortage of hospital beds available for the target patient population. As a result, patients with comorbid disorders were required to resign themselves 


\section{Global Journal of Addiction \& Rehabilitation Medicine}

to hospitalization in standard psychiatric inpatient services $[22,23]$.

It is important, in discussing the findings from this study, that we do not ignore the following issues first, hospitalizations of dual diagnosis patients in standard child and adolescent psychiatric units. Until now there have been no treatment services for adolescents presenting with comorbid psychiatric and substance use disorders. It is possible that the time has come to plan, establish and check the efficacy of integrated dual disorders inpatient services for this population. Second, the lack of dedicated services in the community for those with comorbid disorders during most of the period of the study [29]. This may have been an additional factor in the re-hospitalization of some of those with dual diagnosis, and not always in an integrated dual disorders inpatient service.

Third, it is recommended that the establishment of additional licensed treatment units offering integrative treatment to those with comorbid disorders be seriously considered. During the time that this study was being conducted there were no significant changes in the number and quality of such services being provided in Israel. There is no doubt that the development of additional services, and the expansion of existing ones, will require appropriate funding that will enable suitable staffing, equipment, therapeutic interventions, etc. Excess mortality among patients with severe mental disorders presents a challenge to both clinicians and policy makers [28].

In the spirit of the policy of the World Health Organization (WHO), our series of research studies is designed to identify possible risk factors contributing to excess mortality among dually diagnosed mentally ill patients - after long-term followup. Our previous studies [12,13] illustrated the importance of the seriousness of the phenomenon of excess mortality in this patient subgroup. In the current study, an additional sub-population has been identified; those with comorbid schizophrenia and substance use disorders who were not treated in an integrated dual disorders inpatient service for their health issues in the early stages of their illness, but, rather, in standard psychiatric services.

\section{Limitations of the study}

One of the limitations is that the actual causes of the cases of mortality are not identified. Also, other variables were not studies, e.g. quality of life, vocational rehabilitation, social integration, prevention of hospitalizations, and others. In addition, over a period of 10 years or more, there may have been changes in the conceptualization of treatment for this population of patients; in the context of the beginning of use of drug substitutes, medical substances etc.

\section{Conclusion}

In order to facilitate accessible and available treatment for patients with comorbid psychiatric and substance use disorders, and to increase their rate of long term survival, it is recommended that licensed integrated dual disorders inpatient services be developed and expanded for this patient group with unique treatment needs. The efforts of the Ministry of Health and of the sickness funds to appropriate the integrated dual disorders services to the unique demands of this population should be evaluated again after implementation of the largest mental health care reform in Israel, that has been took place in July 2015.

\section{Acknowledgement}

Ruti Cohen-Zemach - for the help in data collection.

\section{Conflict of interest}

The authors declare that they have no competing interests.

*Note: Presented in part at the $12^{\text {th }}$ Annual Health Policy Conference (2017, May) of the Israel National Institute for Health Policy Research (NIHP), Tel Aviv, Israel and at the annual congress of Israeli Association of Public Health Physicians (2017, June), Tel Aviv, Israel.

\section{References}

1. Lieberman JA, Perkins D, Belger A, Chakos M, Jarskog F, et al. (2001) The early stages of schizophrenia: speculations on pathogenesis, pathophysiology, and therapeutic approaches. Biol Psychiatry 50(11): 884-897.

2. Green AI, Tohen MF, Hamer RM, Strakowski SM, Lieberman JA, et al. (2004) First episode schizophrenia-related psychosis and substance use disorders: acute response to olanzapine and haloperidol. Schizophr Res 66(2-3): 125-135.

3. Lambert M, Conus P, Lubman DI, Wade D, Yuen H, Moritz S, et al. (2005) The impact of substance use disorders on clinical outcome in 643 patients with first-episode psychosis. Acta Psychiatr Scand 112(2): 141-148.

4. Kovasznay B, Fleischer J, Tanenberg-Karant M, Jandorf L, Miller AD, et al. (1997) Substance use disorder and the early course of illness in schizophrenia and affective psychosis. Schizophr Bull 23(2): 195-201.

5. Wade D, Harrigan S, Edwards J, Burgess PM, Whelan G, et al. (2005) Patterns and predictors of substance use disorders and daily tobacco use in first-episode psychosis. Aust N Z J Psychiatry 39(10): 892-898.

6. Wade D, Harrigan S, Edwards J, Burgess PM, Whelan G, et al. (2006) Substance misuse in first-episode psychosis: 15-month prospective follow-up study. Br J Psychiatry 189: 229-234.

7. Archie S, Rush BR, Akhtar-Danesh N, Norman R, Malla A, et al. (2007) Substance use and abuse in first-episode psychosis: prevalence before and after early intervention. Schizophr Bull 33(6): 1354-1363.

8. Pirkko Räsänen, Jari Tähonen, Matti Isohanni, Paula Rantakallio, Jari Lehtonen, et al. (1998) Schizophrenia, alcohol abuse, and violent behavior: a 26-year followup study of an unselected birth cohort. Schizophr Bull 24(3): 437-441.

9. Gimelfarb Y, Natan Z (2009) Risk factors for suicide attempts in dual diagnosis patients. Harefuah 148(6):355-358, 413.

10. Rosenberg SD, Drake RE, Brunette MF, Wolford GL, Marsh BJ (2005) Hepatitis C virus and HIV co-infection in people with severe mental illness and substance-use disorders. AIDS 19 Suppl 3:S26-S33.

11. Gimelfarb Y, Ben Tzarfati M (2017) Impact of hepatitis B (HBV)/C (HCV) virus co-infection on the survival of schizophrenic patients with 
co-occurring substance use disorders followed for 12years. European Psychiatry 41:S862-S863.

12. Gimelfarb Y, Becalel E, Wolf A, Baruch Y (2014) Survival following the first admission in an integrated dual disorders treatment ward (IDDTW): preliminary results from a cohort study. Harefuah 153(3-4): 142-146, 241.

13. Gimelfarb Y, Wolf A, Ben-Tzarfati (2017) Long-term survival of dual disorders patients after mixed care in dual disorders and standard wards versus care in dual disorders ward only. Harefuah 156(1):2226,62 .

14. Chouljian TL, Shumway M, Balancio E, Dwyer EV, Surber R (1995) Substance use among schizophrenic out-patients: prevalence, course, and relation to functional status. Annals of Clinical Psychiatry 7:19-24.

15. Margolese HC, Carlos Negrete J, Tempier R, Gill K (2006) A 12-month prospective follow-up study of patients with schizophrenia-spectrum disorders and substance abuse: changes in psychiatric symptoms and substance use. Schizophrenia Research 83(1): 65-75.

16. Clark RE, Teague GB, Ricketts SK, Bush PW, Xie H, et al. (1998) Costeffectiveness of assertive community treatment versus standard case management for persons with co-occurring severe mental illness and substance use disorders. Health Serv Res 33(5 Pt 1): 1285-1308.

17. Wisdom JP, Manuel JI, Drake RE (2011) Substance use disorder among people with first-episode psychosis: a systematic review of course and treatment. Psychiatr Serv 62(9):1007-1012. doi: 10.1176/appi. ps.62.9.1007.

18. Drake RE, Essock SM, Shaner A, Carey KB, Minkoff K, et al. (2001) Implementing dual diagnosis services for clients with severe mental illness. Psychiatr Serv 52(4): 469-476.

19. Drake RE, Wallach MA (2000) Dual diagnosis: 15 years of progress. Psychiatr Serv 51(9): 1126-1129.

20. Drake RE, O'Neal EL, Wallach MA (2008) A systematic review of psychosocial research on psychosocial interventions for people with co-occurring severe mental and substance use disorders. J Subst Abuse Treat 34(1): 123-138.
21. Bin Nun G, Berlovitz Y, Shani M (2010) The health system in Israel. (2 $2^{\text {nd }}$ ed). Am Oved, Publishers Ltd. Israel, pp 234-235.

22. Ministry of Health.(2009) Mental health in Israel - statistical annual 2008. Jerusalem, Israel. pp 74 - 75.

23. Ministry of Health.(2013). Mental health in Israel - statistical annual 2012. Jerusalem, Israel. pp 70 - 74.

24. Kiviniemi M, Suvisaari J, Pirkola S, Häkkinen U, Isohanni M (2010) Regional differences in five-year mortality after a first episode of schizophrenia in Finland. Psychiatr Serv 61(3): 272-279.

25. Beary M, Hodgson R, Wildgust HJ (2012) A critical review of major mortality risk factors for all-cause mortality in first-episode schizophrenia: clinical and research implications. J Psychopharmacol 5: 52-61.

26. Yuen K, Harrigan SM, Mackinnon AJ, Harris MG, Yuen HP, et al. (2014) Long-term follow-up of all-cause and unnatural death in young people with first-episode psychosis. Schizophr Res 159(1): 70-75.

27. Reininghaus U, Dutta R, Dazzan P, Doody GA, Fearon P, et al. (2015) Mortality in schizophrenia and other psychoses: a 10-year follow-up of the ÆSOP first-episode cohort. Schizophr Bull 41(3): 664-673.

28. Liu N, Dua T (2015) Landscape Analysis: Epidemiology \& Correlates. In: World Health Organization. Meeting report on excess mortality in persons with severe mental disorders. WHO Headquarters, Geneva p. 20-63.

29. Aviram U, Azary-Viesel S (2015) Mental Health Reform in Israel: Challenge and Opportunity. Taub Center for Social Policy Studies in Israel. Policy Paper No. 2015.02.

30. Drake RE, Mercer-McFadden C, Mueser KT, McHugo GJ, Bond GR (1998) Review of integrated mental health and substance abuse treatment for patients with dual disorders. Schizophr Bull 24(4): 589-608.

31. Minkoff K (2001) Program components of a comprehensive integrated care system for seriously mentally ill patients with substance disorders. New Dir Ment Health Serv (91): 17-30.

\section{Your next submission with Juniper Publishers} will reach you the below assets

- Quality Editorial service

- Swift Peer Review

- Reprints availability

- E-prints Service

- Manuscript Podcast for convenient understanding

- Global attainment for your research

- Manuscript accessibility in different formats

( Pdf, E-pub, Full Text, Audio)

- Unceasing customer service

Track the below URL for one-step submission https://juniperpublishers.com/online-submission.php 